\title{
CERVICAL THYMIC CYSTS AND PARATHYROID CYSTS
}

\author{
SHIRO FURUYA and SHOZO BABA \\ Department of Surgery, School of Medicine, Keio University, Tokyo
}

(Received for publication May 8, 1971)

Cysts which originated from embryonal remnants are often observed in the cervical region. Among these cysts, branchiogenic cleft cysts and thyroglossal cysts are most commonly encountered. Parathyroid cysts and cervical thymic cysts are known to be a rare entity. Reviewing the world literature of the latter two, only a few reports were noted. There is, in addition, some confusion in terminology about cysts and cystic formations. We are convinced that parathyroid cysts and cervical thymic cysts should not be included with cystic formations secondary to adenoma or hyperplasia of the gland. Based upon this assumption the following discussions will be made. Since 1961 four parathyroid cysts and one cervical thymic cyst were found in the past 8 years in our clinic. Clinical and histopathological analyses were made on these two types of cysts. There are many resemblances and we would like to conclude that both of these cysts were originally developed from embryonal remnant.

\section{CASE REPORT}

Cases are summarized in Table 1.

\section{A) Parathyroid cysts}

1) 60 year old female. This case has already been reported by Kamegays et al..$^{1}$ Patient noticed a tumor the size of the tip of a thumb in the anterior aspect of the lower neck. She did not complain of any pain. She first visited our Surgical Department on May 16, 1961, when the tumor was excised as an ambulatory patient. It was observed that the tumor was located close to the lower pole of the left thyroid gland, but bore no relationship to the thyroid gland. No adhesions to surrounding tissue were present and the tumor was easily extirpated. Specimen was $2.5 \times 1.5 \times 1.5 \mathrm{~cm}$ in size and encapsulated with a thin wall 
Table 1

\begin{tabular}{|c|c|c|c|c|c|}
\hline \multirow[b]{3}{*}{ Sex } & \multicolumn{4}{|c|}{ Parathyroid cyst } & \multirow{2}{*}{$\begin{array}{c}\text { Cervical } \\
\text { thymic } \\
\text { cyst }\end{array}$} \\
\hline & \multicolumn{3}{|c|}{ Neck } & \multirow{2}{*}{$\frac{\text { Mediastinum }}{\text { Male }}$} & \\
\hline & Female & Female & Male & & Female \\
\hline Age & 60 & 40 & 39 & 64 & 26 \\
\hline Symptom & Tumor & Tumor & Tumor & $\begin{array}{l}\text { drium discom- } \\
\text { fort }\end{array}$ & Tumor \\
\hline $\begin{array}{l}\text { Dis- } \\
\text { function }\end{array}$ & $(-)$ & $(-)$ & $(-)$ & $(-)$ & $(-)$ \\
\hline Position & Left under & Left under & Left under & Left under & Left under \\
\hline Size & $2.5 \times 1.5 \times 1.5 \mathrm{~cm}$ & $4.5 \times 3.5 \times 3.0 \mathrm{~cm}$ & $6.5 \times 5.5 \times 6.0 \mathrm{~cm}$ & Hen egg & Hen egg \\
\hline Adhesion & $(-)$ & $(-)$ & $(-)$ & $(-)$ & $(-)$ \\
\hline $\begin{array}{l}\text { Internal } \\
\text { epithelium }\end{array}$ & $\begin{array}{c}\text { One layer } \\
\text { cuboidal \& } \\
\text { low columnar }\end{array}$ & $\begin{array}{c}\text { One layer } \\
\text { cuboidal \& } \\
\text { low columnar }\end{array}$ & $\begin{array}{c}\text { One layer } \\
\text { cuboidal \& } \\
\text { low columnar }\end{array}$ & $\begin{array}{c}\text { One layer } \\
\text { low columnar }\end{array}$ & $\begin{array}{c}\text { One layer } \\
\text { low columnar }\end{array}$ \\
\hline Contents & $\begin{array}{c}\text { Transparent } \\
\text { fluid }\end{array}$ & $\underset{\text { fluid }}{\text { Transparent }}$ & $\begin{array}{c}\text { Transparent } \\
\text { fluid }\end{array}$ & $\begin{array}{l}\text { Transparent } \\
\text { fluid }\end{array}$ & $\begin{array}{c}\text { Transparent } \\
\text { fuid }\end{array}$ \\
\hline
\end{tabular}

containing clear fluid. Histological studies revealed a thick fibrous connective tissue covered with a layer of cuboidal and low columnar epithelial cells. The cytoplasm was lightly stained with eosin while the relatively small round nucleii were rich in chromatin substance. An almost normal parathyroid tissue was found in the connective tissue and the outer layer. No evidence of inflammatory changes were found (Photo 1).

2) 40 year old female. Patient noticed an asymptomatic tumor about the size of the tip of a small finger at the left supraclavicular region. No treatment was done for 6 months. She was first seen at our clinic in October 1963 when she noticed a growth of the tumor. At that time, BMR was $+9 \%$, PBI $5.39 \mu \mathrm{g} / \mathrm{dl}$ and $131 \mathrm{I}$ uptake $23.5 \%$ respectively. Scintigram revealed a clear-cut defect at the lower portion of the left lobe. The thyroid gland was shifted to the right in general. X-ray demonstrated a right-side deviation of the trachea but no calcifications were found. Slight anemia was present. No liver function impairment was observed. Blood calcium level was within normal limits (4.35 $\mathrm{mEq} / \mathrm{L}$ ). Nothing peculiar was noted in her past history. Operation was performed under the diagnosis of thyroid adenoma on October 29, 1963. A cyst was found about the size of a small hen's egg located close to the lower pole of the left lobe of the thyroid glands. No adhesions were present. Tumor was easily extirpated. Tumor was encapsulated with a thin wall and was $4.5 \times 3.5 \times 3.0 \mathrm{~cm}$ in size, containing a clear fluid. The histopathological finding was almost ident- 
ical to the first case (Photo 2).

3) 39 year old male. Patient was first seen September 24, 1968 with a complaint of a tumor in the neck. Tumor was found in the left supraclavicular region about $5.5 \times 4.0 \mathrm{~cm}$ in size, soft in consistency and elastic, with a smooth surface, and was scarcely movable. PBI was $6.03 \mu \mathrm{g} / \mathrm{dl}$ and ${ }^{131} \mathrm{I}$ uptake was $20 \%$. Scintigram revealed a sharp defect in the lower portion of the left lobe. No calcification was found on X-ray examination which also demonstrated the tracheal deviation to the right. Blood count and liver function tests were within normal limits. Blood calcium was $4.70 \mathrm{mEq} / \mathrm{L}$. Past history was not contributory. November 26, 1968 patient was operated upon under the diagnosis of thyroid adenoma. Findings during the operation were similar to that of the previous cases. A tumor about the size of a goose egg compressed the trachea and it was supplied by the branches of the inferior thyroid artery. Otherwise no relationship to the thyroid gland was observed. Tumor was $6.5 \times 5.5 \times 5.0 \mathrm{~cm}$ in size, encapsulated with a thin wall and contained about $50 \mathrm{cc}$ of clear fluid yellowish in color. The histological study first demonstrated only a thick fibrous layer internally covered with a layer of cuboidal epithelium; however, repeated examinations demonstrated a small amount of parathyroid tissue scattered throughout connective tissue, and also a flattened parathyroid gland in the outer layer. No inflammatory process was observed (Photo 3 ).

B) Parathyroid cysts in the mediastinum

4) 64 year old male. Patient has had a right hypochondrium discomfort intermittently for about 5 or 6 years. Interval of discomfort has gradually been shortened and the patient was examined by a doctor in February 1966. $\mathrm{X}$-ray examination revealed a tumor shadow in the anterior mediastinum. Bronchogram denied the branchogenic origin of the tumor. Blood analysis was normal. Operation was performed on May 15, 1966. Chest was opened at the left VIth rib bed. A dome-like projection of the tumor into the thoracic cavity was found anteriorly to the ascending aorta. No adhesion to the surrounding tissue was found. The tumor was easily removed. The tumor was encapsuled with a thin wall, transparency was observed because of the clear fluid content. The histological study revealed very similar findings to previous cases. Small amounts of tissue of the parathyroid gland were found scattered in the thick fibrous connective tissue. However, it was not possible to demonstrate the presence of the parathyroid gland itself in the outerlayer (Photo 4). 
C) Cervical thymic cysts

5) Y.N. 26 year old female. Patient first noticed a tumor in the anterior aspect of the neck in June 1963, which spontaneously disappeared without any treatment. Next year the tumor reoccurred. She visited our hospital on February 9,1965 . The left clavicle covered the lower half of the tumor with only a small hemispherical portion noticeable. The tumor was about $3 \times 3 \mathrm{~cm}$ in size, with a smooth surface, and was movable, elastic and soft in consistency. Thyroid functions were PBI, $5.78 \mu \mathrm{g} / \mathrm{dl}, \mathrm{BMR}+9 \%$ and ${ }^{131} \mathrm{I}$ uptake $21.4 \%$. A clear defect was observed in the scintigram in the lower portion of the left lobe. Blood count and electrolyte balance were normal. Operation was performed on March 8,1965 . The tumor, hen's egg in size, was found in juxtaposition to the lower portion of left thyroid lobe. The tumor was free of adhesion and was easily extirpated. The removed specimen was a thin-walled cyst containing clear fluid. Histologically the capsule was a fibrous connective tissue with the inner surface covered by a layer of cuboidal and low columnar epithelial cells whose cytoplasm was relatively well stained with eosin and the small round nucleus contained much chromatin. In the outer layer of the fibrous connective tissue, it was observed that there was a considerable amount of almost normal thymus gland tissue. Some of the Hassal corpuscle showed a cystic formation, and was covered interiorly with a flat epithelium with spindle-shaped nucleus. Therefore it was quite easily differentiated from the cuboidal epithelium covering the interior of the cyst. Parathyroid gland was not demonstrated (Photo 5).

\section{DISCUSSION}

About 60 cases of parathyroid cysts have been reported since the first report of Goris (1905).2 However in some of the reports the description of histological findings is not sufficient to establish a diagnosis. About one-third of the reports appear to contain cystic formations due to adenoma or hyperplasia.

In cases involving the thyroid gland, a distinct differentiation had been established between the thyroglossal duct cyst and the cystic formation secondary to adenomatous goiter or thyroid adenoma. The internal surface of the former (true cyst) is covered with epithelium, in contrast to that of the latter which lack an epithelium even if it shows a smooth surface. Therefore the entity of the disease is quite different.

Maxwell $(1952)^{3}$ defined the parathyroid cyst as follows.

1) The occurrence of fields of typical parathyroid cells in the cyst wall.

2) A cyst lining of cuboidal or columnar epitheliums. 
3) The location of the cyst in a position corresponding to that of the parathyroid glands.

Gordon $(1965)^{4}$ also stressed that the cystic formation should be differentiated from the parathyroid cyst, and pointed out the minimum diagnostic criteria.

1) Close proximity to the thyroid gland.

2) A lining of cuboidal or columnar epithelium.

3) The presence of parathyroid tissue in the wall.

Although we would agree in part with both opinions we would modify the criteria as follows.

1) A lining of cuboidal and low columnar epithelium.

2) The presence of the typical parathyroid tissue in the fibrous connective tissue, and the presence of parathyroid gland in the outer layer.

3) Location of the tumor should be within the normal location of the parathyroid gland. 5

Reviewing the world literature some cases do not fit this criteria; therefore, there are some difficulties in analyzing the clinical picture of this disease.

However generally speaking the clinical picture is as follows:

1) Tumor is usually asymptomatic except when it shows the compression symptom.

2) Incidence of location between the right and left sides is the same. All cases except one developed at the lower pole of thyroid gland.

3) It is more commonly found in females than in males.

4) There is no definite age distribution.

In Japan 8 cases were reported, and only one-half of them were considered to fit our criteria. Four cases were diagnosed as parathyroid cyst during 8 years of observation in our experience. We believe that the incidence of this disease is not as uncommon as generally accepted.

McGinty $(1963)^{6}$ stressed that many of the cases are simply handled as a lateral cervical cyst.

Regarding the origin of parathyroid cysts, Haid $(1967)^{7}$ summarized as follows:

I. Congenital origin.

Embryological remnants of the third and fourth branchial clefts.

II. Acquired origin.

1) Enlargement of microcysts because of retention.

2) Coalescence of smaller microcysts.

3) Cystic degeneration in a parathyroid adenoma.

We believe the third statement listed under acquired origin should be ex- 
cluded.

Presently, the theory of retention cyst appears to be the one most acceptable, because small cystic formation occures in normal parathyroid gland.

However, we feel the histological comparison of the internal epithelium is inadequate.

The histochemical study by Fisher and Gruhn $(1957)^{8}$ revealed that, as far as an glycogen metabolism is concerned, internal epithelium was very similar to that of parathyroid gland cells and was different from of epithelium of typical branchiogenic cyst. Based merely on this finding, it is not sufficient to conclude that the internal epithelium originated from the parathyroid gland, since the embryological character of the first and second branchiogenic clefts is different from the rest of the clefts.

We would like to propose a congenital origin upon analysing our cases, for the following reasons.

1) If it were a retention cyst, the fibrous capsule must be a product of reactive proliferation of fibrous tissue. Then the question would naturally arise regarding the presence of a layer of epithelium without any evidence of degenerative or inflammatory reactions.

2) Nylander (1929) 9 also proposed the congenital origin, stating that the parathyroid gland tissue was observed in the fibrous capsule, and thus may be the result of a secondary involvement. Jonassen (1961) 10 disagreed with this opinion; however, we would be inclined to accept it because there is a similarity in the presence of thyroid follicles scattered in the walls of a thyroglossal duct cyst.

3) Our congenital origin theory is based upon the comparative study of the internal epithelium of the cervical thymic cyst and the parathyroid cyst.

About 20 cases of cervical thymic cysts have been reported. Only one case was reported in our country. ${ }^{11}$

Bieger (1966) ${ }^{12}$ reported 12 cases of thymic cysts which included 4 cases of cervical thymic cysts. This cyst was often separated from the adjacent thymus tissue by a structured fibrous tissue free of inflammatory reaction. Bieger concluded that the cervical thymic cyst has its origin from the thymopharyngeal duct system.

The thymopharyngeal duct system was referred to as Kürsteiner's canal by Gilmour (1939). It is connected to the parathyroid gland, thymic gland and thymic cord, and is usually found with parathyroid III and thymus III.

Gilmour (1937) ${ }^{13}$ reported the developmental relationship of parathyroid and thymus in detail. 


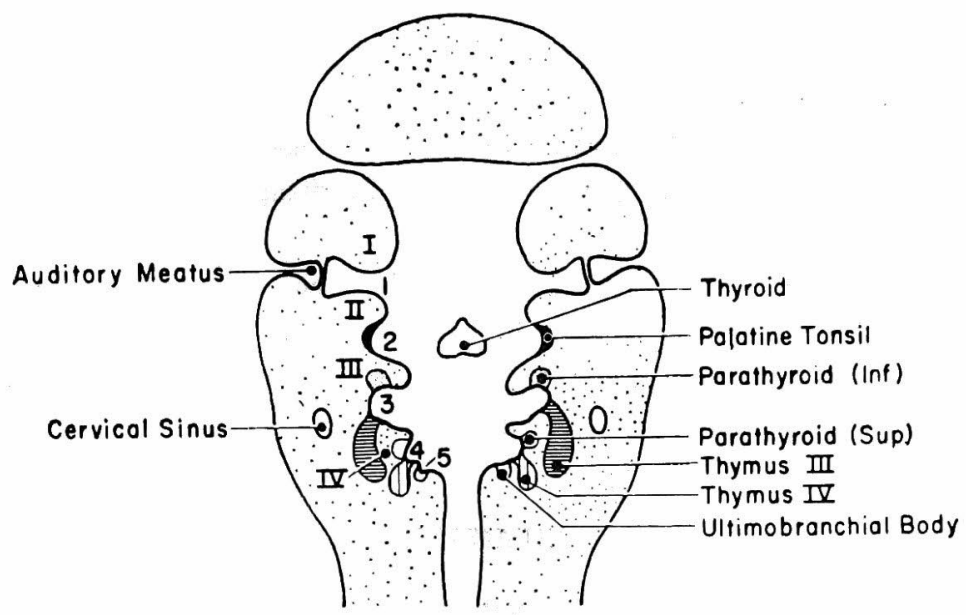

Fig. 1.

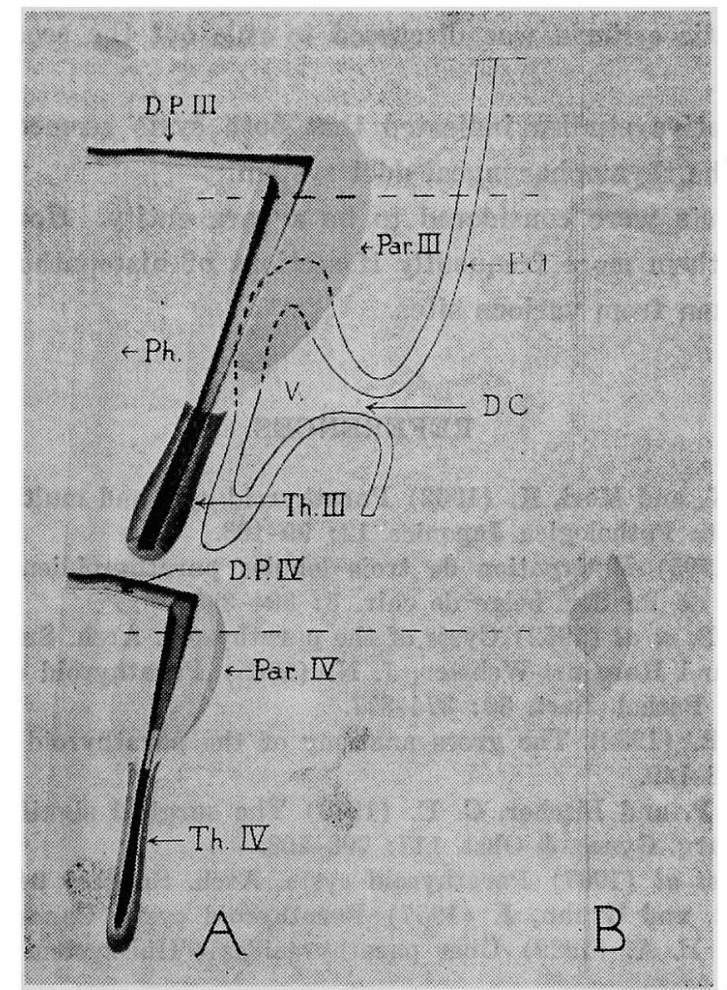

Fig. 2. D.P. III and IV: Ductus pharyngobrachialis III and IV Par. III and IV: Parathyroids III and IV

Th. III and IV: Thymus III and IV 
His study considered that both parathyroid III and thymus III developed from the third branchial arch, which descended caudally and became the inferior parathyroid glands and thymus, respectively. Both parathyroid IV and thymus IV developed from the IVth branchial arch, and parathyroid IV became the superior parathyroid glands. Thymus IV usually disappeared or combined with the thymus III (Figure $\mathbf{1}^{14}$ and $2^{13}$ ).

There is a great similarity between the internal epithelium of parathyroid cysts and cervical thymic cysts (Photo 6 ).

It is for these three reasons, we would like to conclude that parathyroid cysts develop congenitally from the remnant of the thymopharyngeal duct system.

\section{SUMMARY}

1. Four cases of parathyroid cysts and one case of cervical thymic cyst were seen in our hospital during 8 years of observation.

2. Diagnostic criteria was discussed to rule out the secondary change of cystic formation.

3. Comparative studies indicated that both cysts seemed to develop congenitally from the thymopharyngeal duct system.

4. Both cysts were considered to be a rare entity. However, it may be possible to find them more frequently if sections of histopathological specimens are carefully taken from various sites.

\section{REFERENCES}

1. Kamegaya, K. and Mori, K. (1962) Parathyroid cyst and multicystic parathyroid adenoma. Acta Pathologica Japonica 12: 99-103.

2. Goris, D. (1905) Extirpation de trois lobules parathyroidiens kystiques. J. de chir. et ann. de Pa Soc. belge de chir. 5: 394-395.

3. Maxwell, D. B. et al (1952) Cysts of the parathyroid. Arch. Surgery 64: 208-213.

4. Gordon, A. and Harcourt-Webster, J. N. (1965) Parathyroid cysts: A report of two cases. J. Pathol. Bact. 89: 374-377.

5. Gilmour, J. R. (1938) The gross anatomy of the parathyroid glands. J. Pathol, Bact. 46: 133-149.

6. MeGinty, C. P. and Lischer, C. E. (1963) The surgical significance of parathyroid cysts. Surg. Gynec. \& Obst. 117: 703-708.

7. Haid, S. P. et al (1967) Parathyroid cysts. Arch. Surgery 94: 421-426.

8. Fisher, E. R. and Gruhn, J. (1957) Parathyroid cysts. Cancer 10: 57-62.

9. Nylander, P. E. A. (1929) UUber parathyreoideale Halszysten. Acta chir. Scand. 64: $539-547$.

10. Jonassen, O. T. (1961) Parathyroid cysts of clinical significance. Arch. Surgery 83: 758-761. 
11. Ainai, S. et al (1969) Cervical thymic cysts. (in Japanese), GEKA 31: 92-95.

12. Bieger, R. C. and McAdams, A. J. (1966) Thymic cysts. Arch. Path. 82: 535-541.

13. Gilmour, J. R. (1937) The embryology of the parathyroid glands, the thymus and certain associated rudiments. J. Pathol. Bact. 45: 507-522.

14. Simons, J. N. et al (1964) Cervical thymic cyst. Amer. J. Surg. 108: 578-582. 


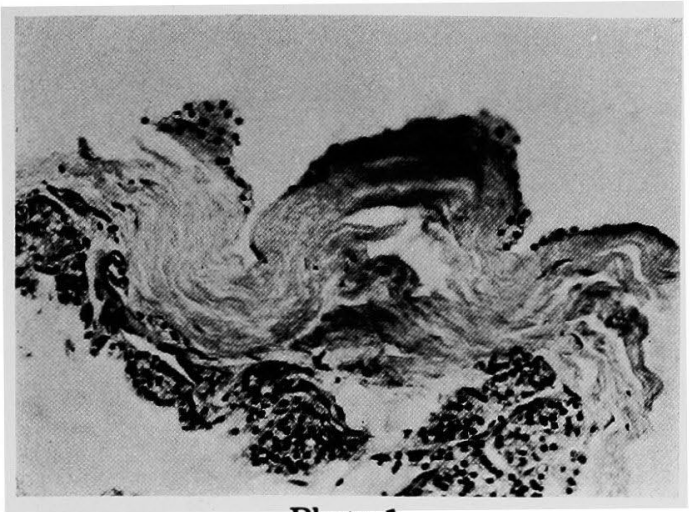

Photo 1

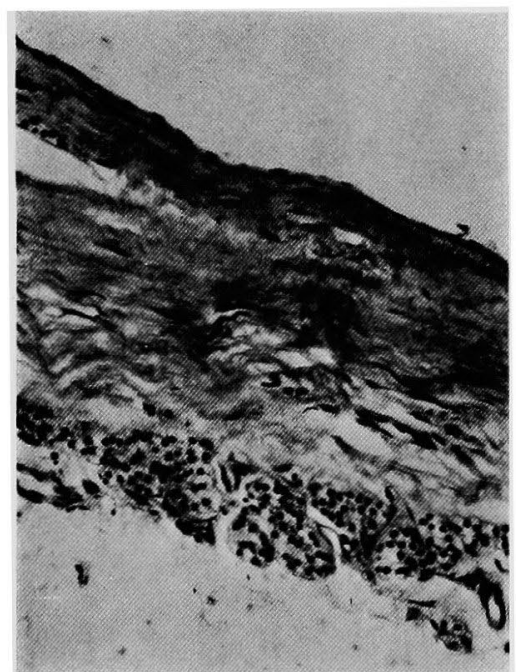

Photo 3

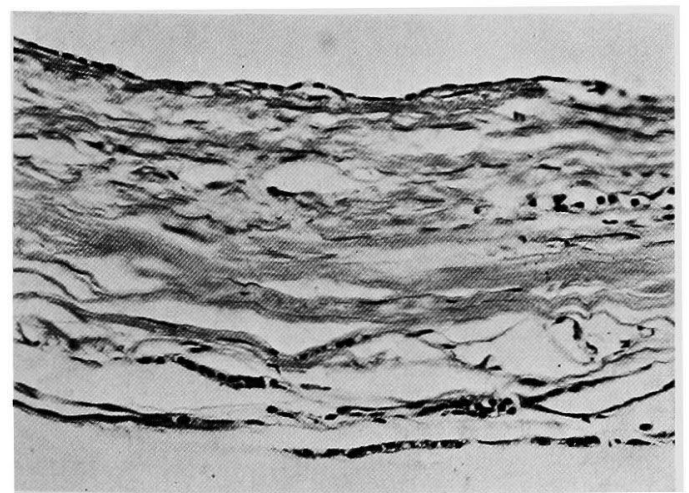

Photo 4

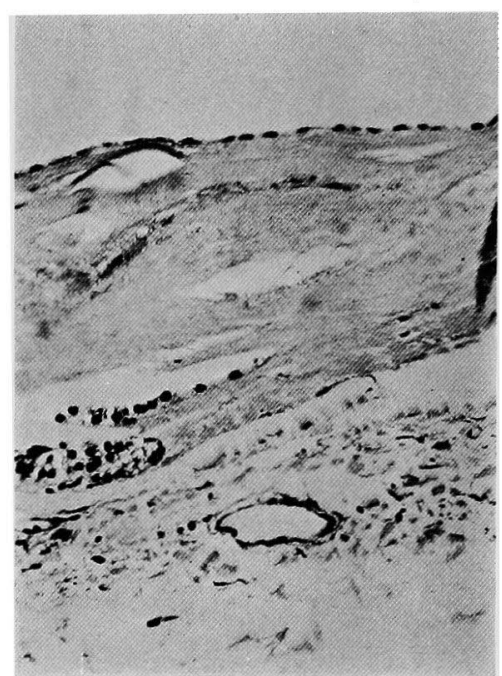

Photo 2

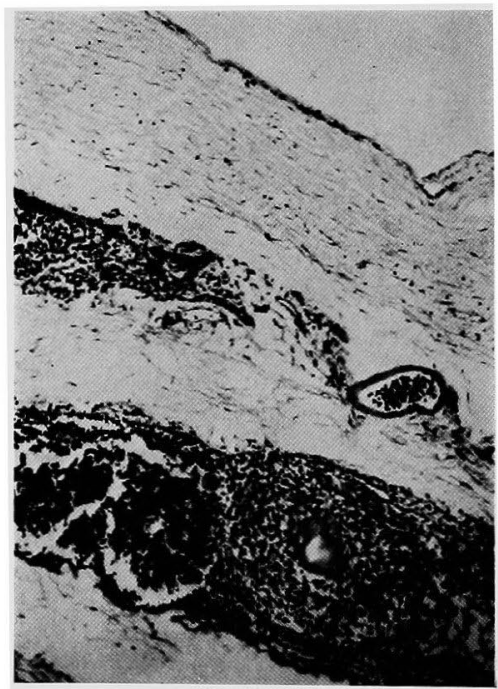

Photo 5 


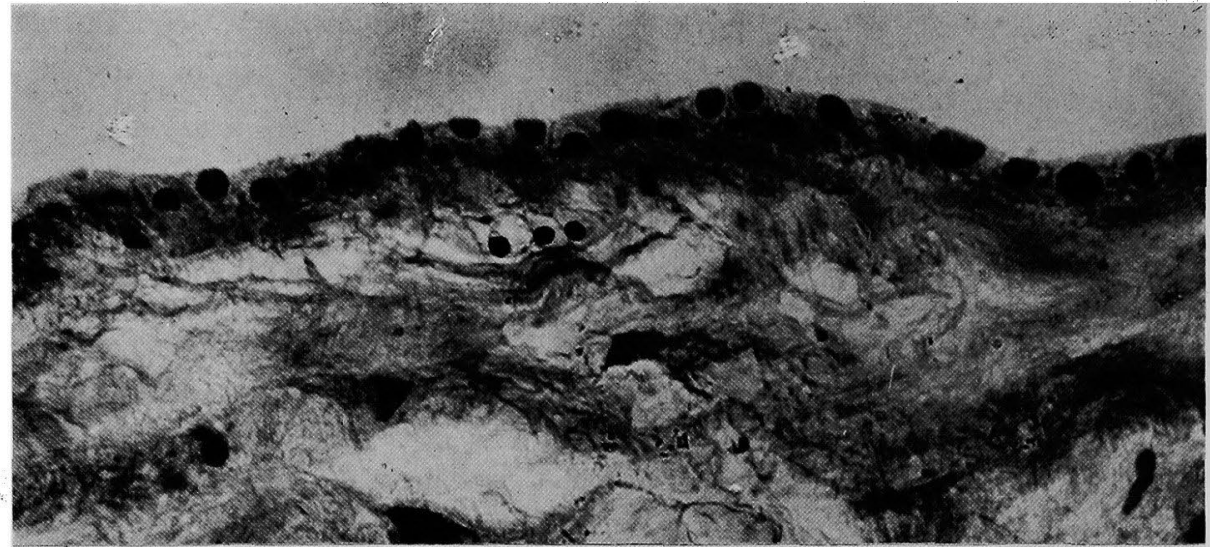

2

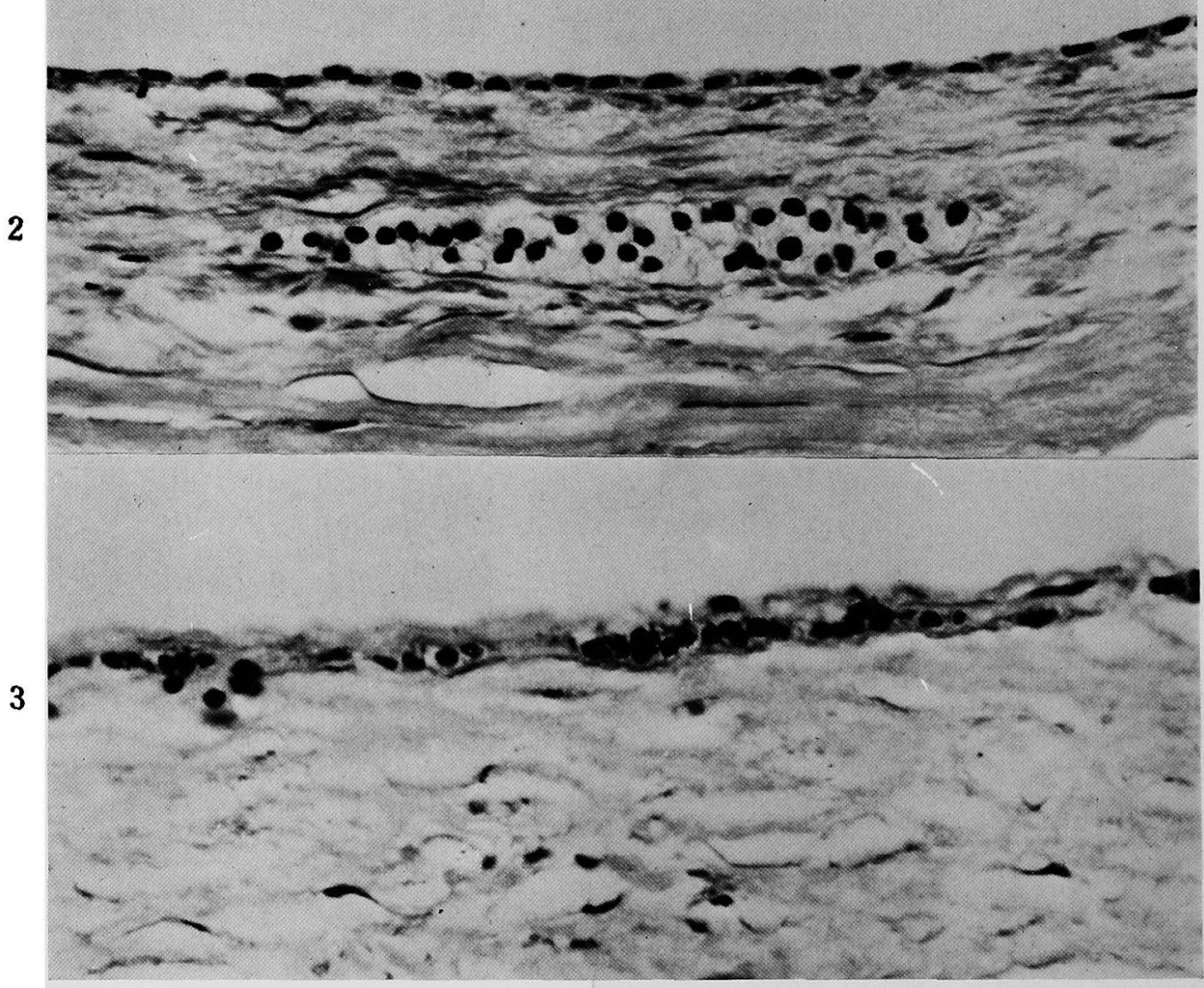

3

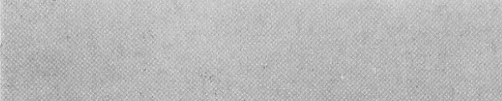

Photo 6

1 and 2 Parathyroid cystst

3 Cervical thymic cyst 